\section{AN UPDATE ON SUGAR}

It's in the news as much as it's in our cakes, orange juice, sweets and fizzy drinks.

Thankfully no-one is campaigning for sugar to be removed from the news agenda. In fact, the Health Select Committee, the government and Public Health England have all helped to drip feed us news on sugar in the exact quantities experts have labelled as unhealthy.

Here a timeline in quotes of the major news concerning sugar...

First of all, Graham MacGregor, Professor of Cardiovascular Medicine at Queen Mary University of London and Chairman of Action on Sugar, said: 'It is absolutely scandalous that the health secretary and NHS officials have refused to publish the scientific review by Public Health England (PHE) on how best to reduce sugar, which includes a proposed sugar tax. Why has this 'hidden secrecy' been allowed to happen?

'For too long, this government has allowed an unregulated food \& drink industry to peddle poor nutrition and high calorie products targeting the most vulnerable members of our society, our children. We now need to fully understand who's determining the country's obesity strategy - is it the food Et drink industry or the government?

'PHE is meant to be an independent body but is clearly taking instruction from Jeremy Hunt, which makes a complete shambles of the organisation.

'What we eat is now the major cause of strokes and heart attacks, obesity and type 2 diabetes and is therefore the biggest cause of death and ill health in the UK. If the issue of imposing a sugar tax is not addressed now, both the government and food \& drink industry will be to blame for bankrupting the NHS. It's as simple as that.'

PHE then published their scientific report, and the British Dental Association (BDA) responded.

Chair of the BDA, Mick Armstrong, said: 'Public health policy must be guided by evidence, not by personal prejudice or commercial interests. Somehow we have allowed tooth decay, an entirely preventable disease, to become the leading cause of hospital admissions among our children. Health professionals expect real leadership here, and no option can be left off the table.

'Britain is addicted to sugar, and inaction can no longer be justified, either morally or financially. Public health and the NHS balance sheet are where we will continue seeing the real cost of political intransigence.'

In the report PHE proposed a sugar tax, and Professor Nigel Hunt, Dean of the Faculty of Dental Surgery responded by saying: 'We are pleased this long awaited report has finally been published and that it considers how we can reduce the impact of sugar on oral health as well as obesity.

'Action to improve diet must happen alongside encouraging visits to the dentist. Almost half of adults and a third of children still do not attend regular dental check-ups. Routine visits are vital to providing diagnosis and treatment.'

\title{
DATE FOR THE DIARY
}

NHS England in conjunction with Health Education Kent, Surrey and Sussex are hosting an event on 18 November at the Park Crescent Conference Centre (229 Great Portland Street, London, W1W 5PN) to focus on unscheduled dental care services. Dr Sara Hurley, Chief Dental Officer for England, will be inviting clinicians, service providers and commissioners to discuss a wide array of topics around unscheduled dental care. The event will allow clinicians and service providers to discuss and compare current models of practice, service challenges and successes. For further details please contact yallen@kss.hee.nhs.uk

\section{SUPPORTING AMR AWARENESS}

European Antibiotic Awareness Day (EAAD) on 18 November is now an established event in the calendar, and this year also sees the World Health Organisation's first World Antibiotic Awareness Week (WAAW; 16-22 November). These campaigns aim to highlight to everyone - from the public and health professionals to governments - the serious threat of antimicrobial resistance (AMR). They will outline the actions we can all take to minimise its spread and preserve the efficacy of existing antibiotics, on which we depend for so many aspects of modern healthcare.

The BDA has engaged directly with the Chief Medical Officer for England, who has been spearheading national and global work on AMR, and highlighted the importance of considering dentistry in her agenda. We have contributed to national policymaking through consultation responses and are entering partnerships with other organisations including Public Health England and the EAAD campaign to synergise our efforts and influence. We urge you to show your support for our work and engage with EAAD and WAAW by taking the Antibiotic Guardian pledge (https://antibioticguardian.com/) and talking to your patients, colleagues, family and friends about the vital importance of using our precious antibiotics wisely.

\section{NOTICE}

We are advised that the photograph in the news item entitled 'Meeting round-up: Undergraduate research in the spotlight ' $(B r$ Dent $J$ 2015; 218: 442) should be credited to Stephanie Bennett.

\section{FGDP(UK) RESPONSE TO NORDIC INSTITUTE RESEARCH INTO RESTORATIONS AND DECAY}

The Faculty of General Dental Practice UK [FGDP(UK)] has welcomed recent research into the effect of restorations on the development of decay in adjacent teeth.

'The study by the Nordic Institute of Dental Materials, published in the Journal of Dentistry, underlines the importance of dentists and patients working together to maintain good oral hygiene', said FGDP(UK) Dean, Mick Horton.

'Dental procedures, like many types of health treatments, can carry risks of side-effects, and we welcome research into this area.

'The findings of the Nordic Institute suggest that there are a number of factors which may influence the risk of developing or worsening decay in teeth adjacent to a restoration, one of which may be a result of operator intervention. There is also strong evidence that poor dietary control and oral hygiene have an influence on whether these areas develop decay. It is important that risk factors are identified and mitigated where possible, and it would be appropriate in light of the findings to consider further research to better understand the causative agents.

'Restorations are not without shortcomings, however in many cases they remain the best available treatment for tooth decay, and I would urge patients not to avoid necessary dental treatment. There is no ideal substitute for an unrestored intact dentition, so by promoting good oral hygiene, maintaining a healthy diet and ensuring the appropriate use of preventative measures, dentists and patients can together help maintain a healthy smile.' 